\title{
Assédio moral no trabalho
}

${ }^{1}$ Editor convidado. Membro do Conselho Editorial da RBSO. Professor no Departement d'Organisation et Ressources Humaines - École des Sciences de la Gestion Université du Québec à Montréal - UQAM, Montreal, Canadá.

${ }^{2}$ Editora convidada. Tecnologista do Serviço de Ergonomia da Fundacentro; Doutoranda em Sociologia pela Faculdade de Filosofia Letras e Ciências Humanas da Universidade de São Paulo, São Paulo, SP, Brasil.

Contato:

Angelo Soares

E-mail:

soares.angelo@uqam.ca
${ }^{3}$ Ver também seu segundo livro que trata especificamente do assédio moral no trabalho (HIRIGOYEN, 2001).

\section{O assédio moral no trabalho: uma breve introdução}

O assédio moral no trabalho é um problema organizacional que, nas últimas décadas, tem tomado proporções importantes nas organizações contemporâneas e tornou-se um tópico essencial para a saúde de trabalhadoras e trabalhadores. O tema tem sido analisado utilizando-se diferentes abordagens, diferentes ângulos de análise, diferentes metodologias, e os artigos presentes neste número da RBSO representam essa diversidade.

Na literatura científica, a primeira tentativa de definição é feita por Brodsky (1976), que define o assédio moral como sendo:

[...] tentativas, repetidas e obstinadas, de uma pessoa para atormentar, quebrar a resistência, frustrar ou obter uma reação do outro. É um tratamento que, com persistência, provoca, pressiona, amedronta, intimida ou incomoda outra pessoa. (p. 2)

Leymann (1996) define o assédio moral como sendo uma sucessão de proposições e gestos hostis que isoladamente podem parecer insignificantes, mas cuja repetição constante provoca efeitos perniciosos. Nesta definição, podemos observar uma característica importante do assédio moral, isto é, quando analisamos separadamente cada um dos gestos que o compõem, corremos o risco de banalizar esta forma de violência, pois, se cada gesto pode nos parecer inofensivo, a sinergia e os resultados da combinação repetida destes gestos vão produzir efeitos destruidores que acabam por "quebrar" psicologicamente a pessoa que foi o alvo do assédio.

Na França, Hirigoyen (1998) define o assédio moral como sendo:

[...] toda conduta abusiva que se manifesta por comportamentos, palavras, atos, gestos e escritos que podem atingir a personalidade, a dignidade ou a integridade física ou psíquica de uma pessoa, colocar em perigo o trabalho desta pessoa ou degradar o clima de trabalho. (p. 55)

Esse primeiro livro de Marie-France Hirigoyen ${ }^{3}$ catalisou um grande movimento social na França que culminou com a criação e a aprovação de uma lei que criminaliza e sanciona o assédio moral no trabalho.

\section{Frequência e duração}

As definições do assédio moral vão enfatizar alguns aspectos que diferenciam esta forma de violência de outras. O assédio moral é um processo dinâmico que se desenvolve no tempo e no qual a frequência e a duração assumem papel importante. 
Desta forma, eventos isolados ou um só gesto geralmente não são considerados como assédio moral. Todavia, esse critério deve ser observado com certo cuidado. Einarssen et al. (2011) chamam a atenção para o fato de que nem todos os gestos associados ao assédio moral são de natureza episódica. Por exemplo, um rumor pode circular e destruir ou ameaçar a carreira ou a reputação da vítima e não necessita de se repetir semanalmente. Os mesmos autores ainda dão o exemplo de pessoas que são colocadas em salas isoladas, sem janelas, sem computadores, sem telefones e muitas vezes sem tarefas a serem realizadas. Na França, esse fenômeno foi investigado e analisado por Lhuillier (2002), que examina a exclusão física, nas organizações, daqueles que são considerados como "inúteis" (porque muitas vezes têm mais idade ou problemas de saúde) ou porque incomodam. Nestes casos, o assédio é um estado permanente ao invés de uma série de eventos ou gestos episódicos.

A duração também tem colocado algumas questões importantes. Por quanto tempo essa violência deve existir para ser considerada como assédio moral? Ou quanto tempo até que se manifestem os efeitos negativos para a saúde das pessoas que foram alvo desta forma de violência? Muitos pesquisadores estabelecem um período de seis meses para que se considere assédio moral, fazendo uma referência ao trabalho de Leymann (1997). É importante salientar que limitar o assédio a esse espaço temporal é um erro, pois o próprio Leymann, nesse documento, ressalta o caráter arbitrário desses seis meses. O autor indica que se trata apenas de uma operacionalização estatística do conceito de assédio.

Assim, ao mesmo tempo em que a frequência e a duração do assédio moral são dimensões importantes a serem consideradas, elas devem ser tratadas com cuidado e, considerando-se a própria dinâmica que pode existir entre essas duas dimensões, por exemplo, se os gestos do assédio acontecem diariamente, talvez após um mês os efeitos sobre a saúde já possam ser observados (BEALE, 2001; ZAPF et al., 2003; TEHRANI, 2012). Pesquisas sobre essas questões ainda são incipientes, como mostram Glina e Soboll neste dossiê.

\section{A intencionalidade do assédio}

Outro aspecto importante é a questão da intencionalidade do assédio moral. As definições de assédio moral não incluem a intencionalidade, pois o assediador nem sempre tem a intenção de assediar, mas, com ou sem intenção, essa violência pode existir e causar dano. Hoel, Rayner e Cooper (1999) discutindo a questão da intencionalidade, mostram que é praticamente impossível verificar sua presença ou não. Verdasca (2010) também salienta que a intencionalidade pode não estar presente, contudo, se ela for percebida pela vítima, isso pode interferir na sua capacidade de identificar um comportamento como sendo ou não assédio moral. A inclusão deste aspecto na própria definição não é adequada dada a dificuldade de constituição de prova.

\section{O gênero do assédio moral}

Um aspecto quase não considerado nos artigos que formam este número da RBSO sobre assédio moral, mas que julgamos importante mencionar, é a questão do gênero do assédio moral.

Embora na literatura ainda não haja um consenso sobre o efeito da variável gênero sobre o assédio moral, quando se tenta responder à questão de quem é mais assediado, homens ou mulheres, vários autores identificam a existência de uma divisão sexual no assédio moral. Um desses aspectos é a frequência dos gestos que compõem o assédio, que parece ser mais elevada para as mulheres (LEYMANN, 1996; SEMAT, 2000). Enquanto a maioria dos homens declara ser assediado uma vez por semana, as mulheres indicam ser assediadas quase cotidianamente. Hirigoyen (2001) considera que os gestos que compõem o assédio das mulheres são diferentes quando comparados aos gestos que formam o assédio dos homens. A mesma autora indica também que muitas vezes o assédio sexual e o assédio moral podem coexistir. Nossas próprias pesquisas também indicam não somente essas diferenças de gênero nos gestos do assédio moral, mas também de idade (SOARES, 2006a, 2006b, 2007).

Outros estudos mostram que não existem diferenças entre quem é mais assediado: homens ou mulheres (QUINE, 2001; VARTIA, 1996; VARTIA; HYYTI, 2002). Em nossas pesquisas também não encontramos essas diferenças (SOARES, 2002, 2004).

Salin (2001), analisando profissionais da gestão na Finlândia, encontrou diferenças na prevalência e na forma do assédio moral. O estudo mostra que não só as mulheres são mais assediadas que os homens, como também são obrigadas a trabalhar abaixo do seu nível de competências profissionais. Elas são mais expostas a fofocas, assim como mais ostracizadas. As mulheres também são mais assediadas pelos subordinados comparativamente aos homens. 


\section{Consequências do assédio moral para a organização}

Para as organizações, as consequências do assédio moral são desastrosas em termos de eficiência e eficácia organizacionais, produtividade e lucratividade de várias maneiras: a princípio, com a perda de tempo, pois enquanto se assedia não se trabalha. Somem-se a isso os gastos elevados incorridos com absenteísmo (KIVIMAKI; ELOVAINIO; VAHTERA, 2000; NAMIE, 2007), perda de produtividade (RAYNER, 2006), rotação da mão de obra (GARDNER; JOHNSON, 2001; NAMIE, 2003), presenteísmo, custos associados à dotação do pessoal, aos prêmios das apólices de seguro, dentre outros gastos (GARDNER; JOHNSON, 2001; MACINTOSH, 2005).

Dois aspectos ainda merecem atenção: o custo associado aos processos por assédio moral (GARDNER; JOHNSON, 2001; RAYNER, 2006) e o impacto negativo na imagem da organização proveniente da publicidade negativa de casos de assédio moral. Essa imagem negativa pode tornar difícil a dotação do pessoal, assim como as relações com a clientela (RAYNER, 2006). Assim, para as organizações, o assédio moral é também um desastre, a nosso ver, ainda hoje subestimado pela administração das organizações.

\section{Consequências do assédio moral para o indivíduo}

As consequências do assédio moral para a saúde da trabalhadora/do trabalhador são devastadoras. O assédio moral tem sido considerado como um dos mais importantes estressores nas organizações contemporâneas. Hoel e Cooper (2000) mostram que as vítimas de assédio moral possuem uma degradação em termos de saúde física e mental quando comparadas com as testemunhas ou os colegas que nunca foram o alvo de assédio moral.

Vítimas de assédio moral mostram um número maior de queixas psicossomáticas: dores de cabeça, dor de estômago, insônia e tontura (MOAYED et al., 2006; YILDIRIM; YILDIRIM, 2007). Hansen et al. (2006) encontraram em sua pesquisa que as vítimas de assédio moral tinham um maior nível de sintomas de depressão, de ansiedade, de afetividade negativa comparativamente as não vítimas de assédio. Neste estudo, foi utilizada a medida da concentração do cortisol na saliva, que era menor na hora do despertar para as vítimas.

Hogh et al. (2012) vão refinar esses resultados demonstrando que o impacto para saúde mental depende dos gestos associados ao assédio moral: isolamento social, assédio direto, intimidação e atos relacionados ao trabalho. O maior impacto para a saúde mental está associado aos atos relacionados ao trabalho.

Kivimaki et al. (2003), em um dos poucos estudos longitudinais sobre assédio moral, estabelecem forte associação entre essa violência e a depressão. Quanto maior a duração do assédio, maior o risco de depressão. Assim, o assédio moral seria um fator etiológico para problemas de saúde mental. Além disso, os autores estabelecem, apenas parcialmente, que as vítimas de assédio moral estão expostas a um maior risco de doença cardiovascular. O excesso de peso foi identificado como um fator que interfere na relação entre o assédio moral e doença cardiovascular.

Em um estudo longitudinal, Vartia (2003) indica também uma correlação entre o assédio moral e a incidência de doença cardiovascular e de depressão. Seus resultados sugerem que o bem-estar psicológico não só das vítimas, mas também das testemunhas era inferior quando comparado aos que nunca viveram o assédio. Quine (2001), estudando enfermeiras no Reino Unido, também verificou sintomas de depressão assim como uma baixa satisfação profissional associados ao assédio moral no trabalho. Niedhammer, David e Degioanni (2006), na França, também estabelecem que, quanto maior a exposição ao assédio moral, maior o risco de sintomas depressivos.

Um aspecto importante merece destaque: alguns estudos indicam que nem todos os gestos constitutivos do assédio moral produzem os mesmos efeitos na saúde das pessoas (EINARSEN; RAKNES 1997; ZAPF et al., 2003).

\section{O estresse pós-traumático e o assédio moral no trabalho}

Segundo o DSM-IV, ${ }^{4}$ o estresse pós-traumático é um estado causado por um evento incomum que inclui uma real ameaça para vida ou para a integridade física de uma pessoa. Este estado é vivido como um medo intenso, um estado de terror e impotência. Seus sintomas principais são: problemas de memória, dificuldade de concentração, sentimento de insegurança, dificuldade para dormir, despertar prematuro, pesadelos etc.

\footnotetext{
${ }^{4}$ Diagnostic and statistical manual of mental disorders - DSM (Manual diagnóstico e estatístico de transtornos mentais). Trata-se de um livro publicado pela Associação Americana de Psiquiatria onde são listadas diferentes categorias de transtornos mentais e critérios para diagnosticá-los. Presentemente a última edição é a IV. A edição V está em discussão. Deve-se salientar que existe um enorme debate com relação ao conteúdo desse livro.
} 
Vários estudos têm apontado como consequência do assédio moral a presença de sintomas associados ao estresse pós-traumático. Os primeiros estudos que estabeleceram essa associação são os de Leymann (1996) e Leymann e Gustafsson (1996). Esses autores compararam 64 vítimas de assédio moral, que procuraram uma clínica para tratamento de trauma, com outros indivíduos que desenvolveram um estresse pós-traumático após viver situações traumáticas. Os autores concluem que as vítimas de assédio moral apresentam um nível de estresse muito elevado e que a intensidade do estresse pós-traumático é comparável ao das vítimas de estupro, em termos de ansiedade, deterioração, impotência e dor psicológica.

Ainda nesse estudo, Leymann e Gustafsson (1996) ressaltam um aspecto importante: o estado de estresse pós-traumático, em uma fase crônica, pode mudar traços da personalidade da pessoa que foi o alvo de assédio moral, podendo levar a um estado depressivo ou obsessional. Trata-se de um dado muito importante, pois, quando encontramos uma pessoa que vive ou viveu o assédio moral, ela pode já estar em um estado de estresse pós-traumático e ter tido traços de sua personalidade alterados. Desta forma, todas tentativas de se identificar traços de personalidade da pessoa-alvo de um assédio moral são, a princípio, problemáticas, pois não se pode estabelecer se tais traços já foram ou não modificados pelo estresse pós-traumático.

A maioria dos indivíduos que vive um estresse pós-traumático tenta evitar tudo aquilo que possa lembrar o assédio, e desenvolve várias estratégias de evitação do problema. Entretanto, apesar de todas essas estratégias, os indivíduos revivem essa história de maneira repetida através de pesadelos e pensamentos intrusivos. Ainda no estudo realizado por Leymann e Gustafsson (1996), 81\% das pessoas que sofreram assédio moral viviam pensamentos intrusivos pelo menos uma vez por semana e 67\% viviam altos níveis de evitação do problema.

Mikkelsen e Einarsen (2002) realizaram um estudo com professores, enfermeiras e representantes sindicais. De 118 vítimas de assédio moral, 30\% tinham sintomas de estresse pós-traumático, segundo a escala Post-Traumatic Diagnostic Scale (PDS), de Foa (1995). Os resultados também mostram que o fato de viver o assédio no momento da pesquisa ou de tê-lo vivido, bem como a sua duração também influenciam no nível dos sintomas de estresse pós-traumático.

Tehrani (2004) realizou um estudo com 165 profissionais da área de saúde. Os resultados mostram que $40 \%$ tinham vivido assédio moral nos últimos dois anos e, destes, $44 \%$ apresentavam sintomas de estresse pós-traumático.

Finalmente, Matthiesen e Einarsen (2004) realizaram uma pesquisa com 102 indivíduos-alvos de assédio moral no trabalho que tinham procurado ajuda em uma organização que dava suporte a vítimas de assédio moral na Noruega. Os resultados mostram que 60\% e 70\% viviam sintomas severos de estresse e de estresse pós-traumático

Embora utilizando escalas diferentes, diferentes estudos, em diferentes sociedades, têm demonstrado uma correlação entre assédio moral e sintomas de estresse pós-traumático.

\section{Suicídio e assédio moral}

Na literatura sobre assédio moral, Leymann (1990) indica que o suicídio pode ser uma das consequências dessa forma de violência. Pompili et al. (2008), na Itália, indicam que as vítimas de assédio moral no trabalho têm um maior risco de suicídio. Esse risco estaria associado ao desespero, à raiva e à impulsividade engendrados pelo assédio moral. Os autores sugerem que as vítimas sejam avaliadas a fim de verificar a presença de ideação suicida.

A partir de dois estudos realizados no Quebec, Soares (2011) indica que, quando o indivíduo vive o assédio moral, a ideação suicida está mais presente. A duração e a frequência do assédio parecem influenciar na aparição dessa ideação.

Na Itália, Balducci, Alfano e Fraccaroli (2009) encontram uma correlação entre assédio moral e ideação suicida e sintomas de depressão. Os autores afirmam que a relação entre o assédio moral e a ideação suicida é mediada apenas parcialmente pela depressão. Sete entre os 107 participantes nesse estudo indicaram já ter feito uma tentativa de suicídio.

Finalmente, Yildirim e Yildirim (2007), em um estudo sobre enfermeiras na Turquia, indicam que 10\% dos participantes já tinham pensado em se suicidar.

A evidência empírica existente sobre assédio moral no trabalho mostra que, nas últimas duas décadas, houve um enorme progresso com um volume importante de publicações. Embora esses estudos tenham utilizado definições e metodologias diferentes, em países diversos, o assédio moral constitui um fator gerador de 
problemas de saúde física e mental nas organizações contemporâneas que merecem ser melhor compreendidos para que possamos agir de maneira mais proativa na sua prevenção.

\section{Os trabalhos que compõem o dossiê}

O conjunto de artigos do dossiê mostra uma pluralidade de setores de atividade: bancos, vigilância privada, serviço público administrativo, serviço público-privado no setor de transportes, o que ajuda a quebrar o mito de que o assédio moral é um problema específico de determinadas atividades ou de atividades precarizadas.

O artigo de Soares e Villela, Assédio moral na perspectiva de bancários, abre este dossiê abordando o assédio moral em bancários, categoria profissional que teve particular aumento dos casos de afastamentos do trabalho por transtornos mentais (SOBOLL, 2008) após passar por processos de reestruturações produtivas. Preenchendo uma lacuna da literatura, as autoras realisaram um estudo de caso de assédio moral em um banco na região Norte do país, investigando como funcionários entendiam este problema, tanto aqueles que se sentiam vítimas, como aqueles que reconheceram o assédio moral vivido pelo colega de trabalho.

Fortino, em Processo de vulnerabilização e danos ao ofício: a modernização do trabalho em questão, estuda um caso exemplar sobre como uma organização pode, justamente em um processo de modernização como o de lean production, destituir de sentido o trabalho daqueles que realizam a atividade fim de uma empresa. A autora estuda o trabalho dos funcionários de empresa de trens de Paris - condutores, vendedores da bilheteria, agentes de recepção, até às funções de escritório -, mostrando que, quando a empresa busca apenas o "prisma [...] da performance e o da rentabilidade econômica - aplicada nas relações de serviço e até mesmo do serviço público é o sentido do trabalho que é afetado" (p. 213). Um forte exemplo é a situação de um trabalhador da bilheteria que é pressionado a fazer com que os clientes não o procurem e comprem seus bilhetes sozinhos em máquinas. Com isso, o próprio trabalhador ajuda a eliminar seu próprio posto de trabalho, vendo-se exposto ao paradoxo de trabalhar bem para o lucro, mas mal para o cliente e também para si mesmo, o que o coloca em um conflito subjetivo, uma situação de "precariedade subjetiva" (p. 213).

A organização do trabalho apareceu claramente como categoria fundamental aos estudos do assédio moral no trabalho. Neste sentido, a gestão que a coordena e que permite o afloramento deste tipo de violência é assunto também relevante neste dossiê. Metzger, Maugeri e Benedetto-Meyer, em Predomínio da gestão e violência simbólica, aprofundam a análise da violência do trabalho argumentando pela necessidade de relacioná-la a processos sociais mais amplos, como o da "dinâmica de gestionarização". A gestão, sendo "um conjunto de princípios de ação apresentados como racionalmente fundados, reputados por otimizar a utilização dos recursos para economizar e/ou acumular capital” (p. 227), pode ser aplicada como uma lógica, ao mesmo tempo em que como uma ideologia, que incide em outros domínios da vida. A explicação sociológica desta dinâmica e da sua produção de violência é fortalecida pela análise de dois casos: "o trabalho nas centrais de teleatendimento e a implementação de um dispositivo de gestão 'total', o Balanced Scorecard, em uma multinacional” (p. 225). Os autores classificam três níveis de gestão nos quais a violência no trabalho pode se manifestar. Um primeiro e mais amplo resultante de "transformações macropolíticas que tornam incontornáveis a introdução e a renovação dos dispositivos de gestão" (p. 225); um segundo, no qual se aplicam os dispositivos necessários para cumprir com as determinações macro-políticas; e um terceiro nível, o da violência simbólica, no qual a gestão violenta não é percebida como violenta, mas como "natural", dando "suporte às práticas das diferentes categorias de ator" que exercem atos de gestão violenta (p. 225). Com isso, os autores explicam quais fatores podem fazer uma organização praticar políticas de gestão que resultem em atos de violência no trabalho, como o assédio moral.

Embora não se dirijam diretamente à questão do assédio moral, tanto Fortino, como Metzger, Maugeri e Benedetto-Meyer tratam de como se produz o solo fértil para este tipo de violência.

Câmara, Maciel e Gonçalves, em Prevenção e combate ao assédio moral entre servidores públicos do estado do Ceará, apresentam uma experiência de prevenção do assédio moral no funcionalismo público. O artigo relata a instalação de uma Comissão Setorial dedicada ao assunto constituída pelos próprios servidores públicos daquele estado. As autoras descrevem os princípios que nortearam a instalação da comissão, comentam seu funcionamento e alguns de seus resultados. Para isso, usam a metodologia qualitativa e quantitativa de análise de entrevistas com servidores que compuseram a comissão e a elaboração de um "discurso do sujeito coletivo" com os resultados encontrados. Desta forma, oferecem-se uma importante fonte de informações sobre a prática da prevenção do assédio moral ao buscar as compreensões dos próprios servidores acerca do assédio moral e suas motivações para compor a comissão e driblarem os desafios de conciliar estes trabalhos com suas atividades normais de trabalho. 
O ensaio de Vieira, Lima e Lima, E se o assédio não fosse moral? Perspectivas de análise de conflitos interpessoais em situações de trabalho, é um exemplo de como o dossiê reflete as múltiplas abordagens teóricas que têm se delineado em torno do tema. À luz de uma crítica acerca das abordagens individualistas sobre assédio moral, que veem no conceito de "personalidade" uma chave central de análise, Vieira, Lima e Lima analisam um caso de assédio moral no setor da vigilância privada. No entanto, os autores não veem como saída enfatizar a força das instituições sociais na causalidade de um assédio moral. Seria preciso um mergulho no estudo da realidade da própria atividade de trabalho para compreender que o assédio moral ocorre dentro de um contexto mais amplo, o da organização de trabalho, esta sim compreendida também como uma categoria analítica central.

Em Intervenções em assédio moral no trabalho: uma revisão da literatura, Glina e Soboll fazem uma sistematização das propostas de intervenção e prevenção presentes nas bibliografias nacional e internacional sobre assédio moral no trabalho entre 2009 e 2010. Considerando que o assédio moral, assim como demais formas de violências no trabalho, são fenômenos multidimensionais, as autoras defendem que "a prevenção/intervenção deveria ter um enfoque mais amplo, incluindo o indivíduo, o trabalho, atividades em nível organizacional e social” (p. 273). Desta forma, destacam em sua revisão três níveis de atuação: "nível 1: indivíduos envolvidos diretamente - assediado(s) e assediador(es); nível 2: grupo, equipe e colegas (interface indivíduo/organização); nível 3: organizações” (p. 273). Os pontos fundamentais são apresentados de forma prática para o leitor que busca conhecimento aplicado. Como não há ainda, no Brasil, análises sobre atuações bem-sucedidas em intervenções sobre assédio moral, as autoras prestam uma inestimável contribuição no avanço sobre as técnicas aplicáveis a este problema, fazendo deste artigo uma leitura obrigatória para pesquisadores e demais profissionais brasileiros que atuem na extinção do assédio moral.

A obra de Vincente Gaulejac (2007), A gestão como doença social, constitui uma referência de base em dois artigos deste dossiê, o de Fortino e o de Metzger, Maugeri e Benedetto-Meyer, e é criticada por outro, o de Vieira, Lima e Lima. A obra recebe também uma resenha, de Moraes, que avalia a sua contribuição sociológica para o debate.

Muito há ainda que ser discutido sobre assédio moral no Brasil, sociedade historicamente marcada por servilidade, patrimonialismo, preconceitos de cor e de gênero, manifestados em diversos âmbitos da vida social, como a família e o trabalho (SOUZA, 2006). Como salientam Glina e Soboll, "não se pode esquecer ainda, que o assédio moral no trabalho é fruto de um momento histórico e de um contexto social e econômico, definidores da forma de organização do trabalho e do desenho das relações humanas neste contexto" (p. 279). Não é um acaso o fato deste dossiê contar com apenas seis artigos, sendo destes apenas quatro brasileiros. Isto significa que há muito ainda por ser feito neste tema no Brasil.

$\mathrm{O}$ crescimento econômico aliado à modernização da gestão como um fim em si mesmo não se traduzem bem-estar - ao menos para os seus trabalhadores. A literatura aqui apresentada demonstra que, ao contrário, ele tem levado ao sofrimento. O assédio moral é um doloroso efeito colateral e um alerta, infelizmente ainda silencioso, de que o benefício de poucos nunca poderá levar o bem-estar para todos.

Boa leitura!

\section{Referências}

APA. Diagnostic and statistical manual of mental disorders. Forth Edition, Text Revision. Washington: American Psychiatric Association, 2000.

BALDUCCI, C.; ALFANO, V.; FRACCAROLI, F. Relationships between mobbing at work and MMPI-2 personality profile, posttraumatic stress symptoms, and suicidal ideation and behavior. Violence and Victims, v. 24, n. 1, p. 52-67, 2009.

BEALE, D. Monitoring bullying in the workplace. In: TEHRANI, N. (Ed.). Building a culture of respect: managing bullying at work. London: Taylor and Francis, 2001. p. 77-94.
BRODSKY, C. M. The harassed worker. Toronto: Lexington Books, 1976.

EINARSEN, S.; RAKNES, B.I. Harassment in the workplace and the victimization of men, Violence and Victims, v. 12, n. 3, p. 247-263, 1997.

EINARSEN, S. et al. The concept of bullying and harassment at work: the European tradition. In: EINARSEN, S. et al. (Eds.). Bullying and harassment in the workplace: developments in theory, research, and practice. London: CRC Press, 2011. p. 3-39.

FOA, E. B. Posttraumatic stress diagnostic manual. Minneapolis, Mn: National Computer Systems Inc, 1995. 
GARDNER, S.; JOHNSON, P. R. The leaner, meaner workplace: strategies for handling bullies at work. Employment Relations Today, v. 28 n. 2, p. 23-36, 2001.

HANSEN, A. M. et al. Bullying at work, health outcomes and physiological stress response. Journal of Psychosomatic Research, v. 60, n. 1, p. 63-72, 2006.

HIRIGOYEN, M.-F. Le harcèlement moral: la violence perverse au quotidien. Paris: Syros, 1998.

HIRIGOYEN, M.-F. Malaise dans le travail: harcèlement moral - démêler le vrai du faux. Paris: Syros, 2001.

HOEL, H.; RAYNER, C.; COOPER, C. L. Workplace bullying. International Review of Industrial and Organizational Psychology, v. 14, p. 189-230, 1999.

HOEL, H.; COOPER, C. Destructive conflict and bullying at work. Manchester: University of Manchester Institute of Science and Technology, 2000.

HOGH, A. et al. Exposure to negative acts at work, psychological stress reactions and physiological stress response. Journal of Psychosomatic Research, v. 73, n. 1, p. 47-52, 2012.

KIVIMÄKI, M.; ELOVAINIO, M; VAHTERA, J. Workplace bullying and sickness absence in hospital staff. Occupational and Environmental Medicine, v. 57, n. 10, p. 656-660, 2000.

KIVIMÄKI, $M$ et al. Workplace bullying and the risk of cardiovascular disease and depression. Occupational and Environmental Medicine, v. 60, n. 10, p. 779-783, 2003.

LEYMANN, H. Mobbing and psychological terror at workplaces. Violence and Victims, v. 5, n. 2, p. 119126, 1990.

LEYMANN, H. Mobbing: la persécution au travail. Paris: Seuil, 1996.

LEYMANN, H. Explanation of the operation of the LIPT Questionnaire (Leymann Inventory of Psychological Terror). Tradução do original alemão: Helga Zimmermann. South East Queensland, Australia: Griffith University, 1997.

LEYMANN, H; GUSTAFSSON, A. Mobbing at work and the development of post-traumatic stress disorders. European Journal of Work and Organizational Psychology, v. 5, n. 2, p. 251-275, 1996.

LHUILIER, D. Les placardisés. Paris: Seuil, 2002.

MACINTOSH, J. Experiences of workplace bullying in a rural area. Issues in Mental Health Nursing, v. 26, n. 9, p. 893-910, 2005.

MATTHIESEN, S. B.; EINARSEN, S. Psychiatric distress and symptoms of PTSD among victims of bullying at work. British Journal of Guidance $\mathcal{E}$ Counselling, v. 32, n. 3, p. 335-356, 2004.

MIKKELSEN, E. G.; EINARSEN, S. Basic assumptions and symptoms of post-traumatic stress among victims of bullying at work. European Journal of Work and Organizational Psychology, v. 11, n. 1, p. 87-111, 2002.
MOAYED, F. A. et al. Workplace bullying: a systematic review of risk factors and outcomes. Theoretical Issues in Ergonomics Science, v. 7, n. 3, p. 311-327, 2006.

NAMIE, G. Workplace bullying: escalated conflict. Ivey Business Journal, v. 68, n. 2, p. 1-6, 2003.

NAMIE, G. The challenge of workplace bullying. Employment Relations Today, v. 34, n. 2, p. 43-51, 2007. NIEDHAMMER, I.; DAVID, S.; DEGIOANNI, S. Association between workplace bullying and depressive symptoms in the French working population. Journal of Psychosomatic Research, v. 61, n. 2, p. 251-259, 2006.

POMPILI, M. et al. Suicide risk and exposure to mobbing. Work: A Journal of Prevention, Assessment and Rehabilitation, v. 31, n. 2, p. 237-43, 2008.

QUINE, L. Workplace bullying in nurses. Journal of Health Psychology, v. 6, n. 1, p. 73-84, 2001.

RAYNER, C. What does bullying cost your business? People Management, v. 12, n. 24, p. 28, 2006.

SALIN, D. Prevalence and forms of bullying among business professionals: a comparasion of two different strategies for measuring bullying. The European Journal of Work and Organizational Psychology, v. 10, n. 4, p. $425-441,2001$.

SEMAT, È. Femmes au travail, violences vécues. Paris: Syros. 2000.

SOARES, A. Quand le travail devient indécent: le harcèlement psychologique au travail. Performances, n. 3, p. 16-26, mars-avril 2002.

SOARES, A. Comme $2+2=5$ - Le harcèlement psychologique chez les ingénieurs d'Hydro-Québec: les conséquences. Performances, n. 18, p. 30-38, 2004.

SOARES, A. Les bleus à l'âme: le harcèlement psychologique chez les cols bleus de la ville de Montréal. Montreal: Université du Québec à Montréal, 2006a. (Relatório de pesquisa). Disponível em: <http://www.angelosoares.uqam.ca/upload/files/ Rapports\%20de\%20recherche/Les_bleus_a_lame_le_ harcelement_chez_les_col_bleus.pdf $>$. Acesso em: 12 dez. 2012.

SOARES, A. Le sexe et l'âge du harcèlement psychologique au travail. 2006b. Conferência proferida na International Conference on Violence against Women: diversifying social responses. Interdisciplinary Research Centre on Family Violence and Violence against Women (CRI-VIFF), Montréal, Canadá, 23 out. 2006.

SOARES, A. Le harcèlement psychologique a-t-il un âge? In: Tremblay, D.-G. D'une culture de retraite vers un nouveau management des âges et des temps sociaux. Québec: Presses de l’Université du Québec, 2007, p. 153-166.

SOARES, A. Assédio moral e ideação suicida. In: BARRETO, M.; NETTO, N. B.; PEREIRA, L. B. Do assédio moral à morte de si: significados sociais do 
suicídio no trabalho. São Paulo: Matsunaga, 2011. p. 203-219.

SOUZA, J. A invisibilidade da desigualdade brasileira. Belo Horizonte: UFMG, 2006.

TEHRANI, N. Bullying: a source of chronic posttraumatic stress? British Journal of Guidance $\mathcal{E}$ Counselling, v. 32, n. 3, p. 357-366, 2004.

TEHRANI, N. Introduction to workplace bullying. In: Tehrani, N. Workplace bullying: symptoms and solutions. London: Routledge, 2012. p. 1-17.

VARTIA, M. The sources of bullying - psychological work environment and organizational climate. European Journal of Work and Organizational Psychology, v. 5, n. 2, p. 203-214, 1996.

VARTIA, M. Workplace Bullying - a study on the work environment, well-being and health. 2003. $68 \mathrm{f}$. Tese (Doutorado em Psychology)-Department of Psychology, University of Helsinki, Helsinki, 2003. (People and Work Research Reports 56. Helsinki: Finnish Institute of Occupational Health, 2003)
VARTIA, M. \& HYYTI, J. Gender differences in workplace bullying among prison officers. European Journal of Work and Organizational Psychology, v. 11, n. 1, p. 113-126, 2002.

VERDASCA, A. T. M. Assédio Moral no Trabalho: Uma Aplicação ao Sector Bancário Português. 2010. 382 f. Tese (Doutorado em Sociologia Econômica e das Organizações)-Instituto Superior de Economia e Gestão, Universidade Técnica de Lisboa, Lisboa, 2010.

YILDIRIM, A.; YILDIRIM, D. Mobbing in the workplace by peers and managers: mobbing experienced by nurses working in healthcare facilities in Turkey and its effect on nurses, Journal of Clinical Nursing, v. 16, n. 8, p. 1444-1453, 2007.

ZAPF, D. et al. Empirical findings on bullying in the workplace. In: EINARSEN, S. et al. (Eds.). Bullying and emotional abuse in the workplace: international perspectives in research and practice. London: Taylor and Francis, 2003. p. 103-126. 
Errata

Revista Brasileira de Saúde Ocupacional, volume 37, número 126, jul./dez. 2012.

\section{Página 195}

Na afiliação de Juliana Andrade Oliveira, onde se lê:

${ }^{2}$ Editora convidada. Tecnologista do Serviço de Ergonomia da Fundacentro, São Paulo, SP, Brasil.

Leia-se:

${ }^{2}$ Editora convidada. Tecnologista do Serviço de Ergonomia da Fundacentro; Doutoranda em Sociologia pela Faculdade de Filosofia Letras e Ciências Humanas da Universidade de São Paulo, São Paulo, SP, Brasil.

\section{Página 339}

Onde se lê:

"Agradecimentos aos consultores ad hoc desta edição",

Leia-se:

"Agradecimentos aos consultores ad hoc deste volume". 